ESJ Social Sciences

\title{
Competencias Digitales Estudiantiles Ante la Educación Virtual en Tiempos de Pandemia de Covid-19. Caso de Estudio Educación Técnica y Tecnológia
}

\author{
Edwin Alberto Cantos Sánchez \\ Ingeniero Agrónomo, Magister En Sistemas Integrados de Gestión, \\ Universidad Agraria del Ecuador, Docente Contratado \\ Jorge Tarquino Erazo Rivera
}

Licenciado En Educación Mención Lengua Inglesa Y Lingüística, Magister en Tecnología e Innovación educativa, Universidad Agraria del Ecuador docente contratado, Docente Contratado

David Jesús Macías Hernández

Magister En Agroecología Y Agricultura Sostenible, Universidad Agraria del Ecuador, Docente Contratado Gema Carolina Correa Carolina

Licenciada En Ciencias De La Educación Mención Educación Parvulario Maestra En Administración De La Educación, Docente Sabina Florencia Montiel Holguín

Magister en Gerencia y Liderazgo Educacional, Diploma Superior en Gestión para el Aprendizaje Universitario, Licenciatura en Ciencias de la Educación Mención: Lengua y Literatura, Subsecretaria de Educación Distrito Guayaquil Zona 8, Asesora Educativa

Doi:10.19044/esj.2021.v17n32p273

Submitted: 24 August 2021

Accepted: 10 September 2021

Published: 30 September 2021
Copyright 2021 Author(s)

Under Creative Commons BY-NC-ND

4.0 OPEN ACCESS

Cite As:

Cantos Sánchez E.A., Erazo Rivera J.T., Macías Hernández D.J., Correa Carolina G.C. \& Montiel Holguín S.F. (2021). Competencias Digitales Estudiantiles Ante la Educación Virtual en Tiempos de Pandemia de Covid-19. Caso de Estudio Educación Técnica y Tecnológia. European Scientific Journal, ESJ, 17 (32), 273.

https://doi.org/10.19044/esj.2021.v17n32p273

\section{Resumen}

El presente trabajo de investigación tiene como finalidad obtener una caracterización y descripción de grupos, determinando el nivel de desarrollo de las competencias digitales en una institución superior tecnológica ecuatoriana, teniendo relación con la importancia y uso de la utilización de las 
TICS por parte del aprendizaje, haciendo contexto de la educación superior del siglo 21. Para ello, la encuesta realizada a los estudiantes del Instituto Técnico Superior Juan Bautista Aguirre consistieron en Competencias Digitales Básicas (COBADI®) y variables categóricas, participaron 1.408 estudiantes de carreras técnicas y tecnológicas, la metodología que se utilizó en el presente estudio es mixta, ya que se realizó un análisis descriptivo, con un enfoque cuantitativo, donde las etapas se basan principalmente en un proceso de análisis de datos, los resultados del estudio evidencian independientemente del sexo y rango de edad de los estudiantes, determina que existen cuatro grupos claramente diferenciados o formas de uso y consumo de las TICS de diferentes manera para realizar actividades, tanto personales como académicas, los cuales ayudan a identificar diferentes desarrollos de competencias digitales. Este estudio ayuda y permite determinar una línea de base que sirva para poder trabajar posteriormente en el desarrollo de las competencias digitales que sean necesarias en los institutos, las cuales deben ser realizadas por los estudiantes.

Palabras claves: Competencias digitales; Análisis de los datos; TIC; Tecnología; Aprendizaje 


\title{
Competencias Digitales Estudiantiles Ante la Educación Virtual en Tiempos de Pandemia de Covid-19. Caso de Estudio Educación Técnica y Tecnológia
}

\author{
Edwin Alberto Cantos Sánchez \\ Ingeniero Agrónomo, Magister En Sistemas Integrados de Gestión, \\ Universidad Agraria del Ecuador, Docente Contratado
}

\section{Jorge Tarquino Erazo Rivera}

Licenciado En Educación Mención Lengua Inglesa Y Lingüística, Magister en Tecnología e Innovación educativa, Universidad Agraria del Ecuador docente contratado, Docente Contratado

\section{David Jesús Macías Hernández}

Magister En Agroecología Y Agricultura Sostenible, Universidad Agraria del Ecuador, Docente Contratado Gema Carolina Correa Carolina

Licenciada En Ciencias De La Educación Mención Educación Parvulario Maestra En Administración De La Educación, Docente

Sabina Florencia Montiel Holguín

Magister en Gerencia y Liderazgo Educacional, Diploma Superior en Gestión para el Aprendizaje Universitario, Licenciatura en Ciencias de la Educación Mención: Lengua y Literatura, Subsecretaria de Educación Distrito Guayaquil Zona 8, Asesora Educativa

\begin{abstract}
The purpose of this research work is to obtain a characterization and description of groups, determining the level of development of digital competences in an Ecuadorian higher technological institution, having relation to the importance and use of the use of ICT by learning, making context of 21 st century higher education. For this, the survey carried out to the students of the Juan Bautista Aguirre Higher Technical Institute consisted of Basic Digital Competences (COBADI®) and categorical variables, 1,408 students of technical and technological careers participated, the methodology that was used in the present study is mixed, since a descriptive analysis was carried out, with a quantitative approach, where the stages are mainly based on a data analysis process, the results of the study are evidenced regardless of the sex and age range of students, determines that there are four groups clearly differentiated or forms of use and consumption of ICT in different ways to carry out activities, both personal and academic, which help to identify different developments of digital skills. This study helps and allows to determine a baseline that serves to be able to work later in the development of
\end{abstract}


the digital skills that are necessary in the institutes, which must be carried out by the students.

Keywords: Digital skills; Learning; Data analysis; TIC; Technology; Learning

\section{Introduction}

La relación con la gestión del tiempo, la autoeficacia y las competencias digitales están orientadas con la velocidad del avance de las tecnologías, por tanto, la sociedad del conocimiento tiene por obligación adaptarse y familiarizarse con códigos, los cuales son cada vez más complejos, pero imprescindibles al momento de resolver problemas siendo más específicos. De forma que, las competencias digitales en los estudiantes de educación superior juegan un papel importante en la adaptación de este proceso en los entornos pedagógicos.

En continuidad, la competencia digital son conocimientos prácticos dominados que nos permite utilizar las actitudes, conocimientos y los procesos relacionados con las tecnologías de la información y la comunicación, mediante los cuales los estudiantes adquieren habilidades para hacer fácil la transferencia de conocimientos y generar la innovación. En concreto, uno de los modelos teóricos de más uso es el marco propuesto por la Comisión Europea llamado DigComp, el cual afirma que la competencia digital es el aumento de las competencias relacionadas con el conocimiento y la utilización de las áreas relacionadas con la información, comunicación y colaboración, también crear contenidos digitales, seguridad y resolución de problemas.

Según Escobar J. y Mira Y. (2020) afirman que el desarrollo de esta competencia es importante en el sentido de que se tiene en cuenta la forma en que esta sociedad interactúa con el mundo global, tanto en el entorno profesional como en la vida, es decir, generalmente están cambiando a grandes ritmos, tanto así que se requiere la formación de estas habilidades, para poder adaptarse al impacto que la tecnología está logrando tener en estas áreas.

Es de mucha curiosidad pensar cómo actualmente la generación de estudiantes universitarios, los cuales que son caracterizados por ser nativos digitales debido a que han crecido de la mano con la tecnología y que en consecuencia por tener un alto grado de afinidad con las tecnologías de la información, son los que pueden presentar mayores niveles de competencia digital. No obstante, usualmente se determina que existe un alto porcentaje de ellos que no son capaces de extraer una utilidad significativa de estas herramientas, por una parte, se debe a la escases de las herramientas que se usan, alejándose realmente de las mejores técnicas y recursos que podrían usarse para propósitos académicos. 
Sin embargo, este grupo de nativos digitales reconoce con facilidad la utilidad de estas herramientas, pero al mismo tiempo, reconoce el factor distractor (redes sociales, juegos, blogs, etc.) que incide en el proceso de aprendizaje y que genera una pérdida de tiempo. No obstante, este flujo continuo de información hace que el usuario ponga su atención al software de arranque y cree ciclos de verificación constantes y no gestiona correctamente su tiempo.

Esta manera de interactuar con el mundo de la globalización, en el cual cuentan con una amplia variedad de herramientas y sobre todo con fuentes de información a disposición en corto tiempo, requiere a la vez un control estricto del entorno en el cual se desenvuelven estos procesos, ya que es de mucha facilidad realizar, equivocarse, desviar y distraer, siendo de necesidad para gestionar eficazmente algunos recursos que son limitados, por ejemplo: el tiempo (Martínez \& Garcés, 2020). Algunos estudios determinan que lo fundamental en el campo de la tecnología y los ordenadores no es el tiempo que se pasa con ellos, sino la utilización que se hace de ellos, ya que cuando se utilizan directamente en los procesos de aprendizaje y enseñanza, tal como señalan algunas investigaciones realizadas, contribuyen a un ahorro, es decir, una cantidad de tiempo importante a diferencia de si no se la utiliza.

Por tanto, se considera de mucha importancia enseñar a los estudiantes este tipo de habilidades tecnológicas, con la finalidad de prepararlos tanto para el correcto desempeño en la universidad como para el futuro profesional, evitar de esta manera la falta de fijación de los objetivos y la falta de organización de multitarea. En continuidad, uno de los temas que tiene estudio reiteradamente en los últimos años en torno al aprendizaje digital, hace referencia a los factores que inciden directamente en la calidad y al éxito de la educación tecnológica, se determina como factores clave más significativos de la comunicación para los alumnos entre otros compañeros a la gestión del tiempo, control sobre el tiempo, ritmo de aprendizaje, motivación y las expectativas de eficiencia o eficacia.

En la actualidad, ha comenzado a existir un marco común de capacidades digitales. En el nivel superior (C2) de esta capacidad, se ha requerido a los evaluados utilizar recursos técnicos y no técnicos para optimizar el tiempo máximo que emplean para este fin. En esta gestión del tiempo se debe entender como el esfuerzo que realizan los estudiantes por organizar la utilización del tiempo de la forma más eficiente posible, para aumentar la probabilidad de cumplir importantes objetivos educativos en un período de tiempo establecido. Sin embargo, en otros estudios, se ha evidenciado que los docentes, son quienes han ido conociendo las posibilidades que brindan las nuevas tecnologías y han sabido gestionar mejor el tiempo que tienen (Castillo, Peña, Avalos, Méndez, \& Macías, 2017). 
Por el contrario, las personas creen que tener tan buena capacidad para administrar los recursos técnicos y funcionales (como el tiempo) debe tener un mayor sentido de eficiencia en las tareas realizadas; por lo tanto, este sentido de autoeficacia se entiende como la experiencia y percepción sobre la capacidad para afrontar una tarea, dichos que son los juicios que hace uno mismos.

Asimismo, en los últimos años se está evidenciando cómo el correcto uso de las Tecnologías de la Información y la Comunicación (TIC) puede lograr conducir a una mejor autoeficacia y logro académico por medio del establecimiento de un límite de tiempo establecido por día (Huizar \& De la Torre, 2020); (Pinares, 2018); (Luna, 2021). Además, algunos de estos estudios realizados apuntan a la existencia de una correlación positiva tanto en la gestión del tiempo y sobre todo en la autoeficacia percibida, e incluso establecen que existe una posible causalidad entre ambos de manera que personas con peor gestión del tiempo, pocas habilidades organizativas, como también una escasa capacidad para regular las emociones, podrían generar un impacto negativo en la autoeficacia percibida (Segura \& Escudero, 2017). No obstante, en esta línea, existen discrepancias con estudios que se muestran mediante herramientas digitales ya que lograron fomentar la gestión del tiempo en la mayoría de los estudiantes, pero no lograron mejorar la autoeficacia, es decir, la capacidad de autorregulación del aprendizaje.

Según Salas C. (Salas, 2020) los estudiantes sin ningún tipo de metas no sufrirán problemas de tiempo ya que no tienen intención de moverse para ninguna dirección. Sin embrago, también los estudiantes con objetivos difusos podrían perdiendo el tiempo, por esa razón, se considera que establecer metas y objetivos claros, mensurables y alcanzables dentro del límite de tiempo es un paso eficaz para administrar el tiempo que puede disminuir el estrés de las personas.

Durante los últimos años, se ha evidenciado cómo existe una correlación e incluso una predicción positiva entre la autoeficacia y estrés, siendo una correlación negativa y de causalidad entre autoeficacia y la angustia, siendo esta forma moderada por géneros donde las mujeres tienen más probabilidades de estar influenciadas por el estrés académico que los varones. Esta última hipótesis aún se encuentra en discusión ya que se ha demostrado cómo otros estudios no obtuvieron diferencias precisas de las estadísticas significativas entre autoeficacia y estrés, de la misma manera, cabe destacar cómo las organizaciones que fomentan el bienestar del personal se encuentran en constante mejora de la eficiencia laboral y reduciendo los niveles de desgaste entre estrés y ansiedad.

Además, la educación superior se encuentra experimentando constantemente transformaciones sociales y culturales, por tanto, cada vez que aparece un modelo diferente para afrontar los problemas que se muestren 
dentro del aula o en el ámbito de la gestión educativa, se advertirá la recepción e incorporación de dichos modelos a la tarea docente. En la actualidad y tras los avances científicos, tecnológicos y sociales, es evidente encontrarnos en la era de la tecnología, donde se muestran los altos estándares de conocimientos y habilidades que deben adquirirse y deban mostrarse en el desempeño de cualquier tipo de profesión. Sin embargo, el mundo ha demostraron que, el desarrollo de habilidades digitales es muy útil para los estudiantes porque ayudan a resolver problemas particularmente complejos (Diez \& Cabrera, 2021).

Actualmente, se ha vuelto imprescindible enseñar e instruir la formación de personas para que gestionen el conocimiento y logren ser competentes, hábiles, creativos y críticos; que sepan utilizar las habilidades, logren resolver problemas, y así demuestran el aprendizaje que han logrado obtener, estas ideas se reflejan en las agendas educativas tanto nacionales como internacionales (Ministerio de Educación, 2017); OCDE (Organización para la Cooperación y el Desarrollo Económicos), OEI (Organización de Estados Iberoamericanos), UE (Unión Europea) y UNESCO (Organización de las Naciones Unidas para la Educación, la Ciencia y la Cultura). PISA, Metas 2021, Espacio Europea de Educación Superior y Educación 2030, donde priorizan el desempeño de los estudiantes; tanto que refleja con claridad la adquisición de competencias. Logrando tener en cuenta que en esta década prevalece en la sociedad moderna un enfoque orientado al desarrollo de las habilidades complejas a nivel tecnológico, por tanto, es de mucha importancia preparar a los estudiantes para que sean capaces de lograr el desarrollo y aplicación de pensamiento mediante el razonamiento crítico, creativo y divergente, sobre todo para conocer el camino de la lógica, deducción, inducción y el método científico que nos ayuda a resolver problemas (Chee, y otros, 2021).

Ante este dinamismo, todas las instituciones educativas tienen que reestructurar las prácticas y procesos pedagógicos para dar respuesta al impacto que estos avances tienen en el sistema. De alguna forma, la implementación de nuevas herramientas digitales hace contribución a la preparación de estudiantes que están comprometidos con el área profesional, pero también a la formación de las personas competentes que son capaces de enfrentar situaciones con soluciones innovadoras y sobre todo que están dispuesto a resolver problemas, formando parte de las tareas esenciales que las instituciones de educación superior deben tener siempre en cuenta.

La definición sobre las competencias varía según las diferentes opiniones de los autores; el contexto; la concepción ha variado ligeramente según el campo de estudio a lo largo del tiempo, por tanto, en consideración a lo establecido por diferentes autores en el campo educativo, la definición de competencia es entendida como una relación entre el actor o público objetivo, 
los conocimientos y las habilidades (Segura \& Escudero, 2017). En esta relación se comprende que los conocimientos y habilidades aplicados sumando las características personales del individuo, son usados en una determinada tarea y en la resolución efectiva de situaciones, con el objetivo de responder a circunstancias desde el propio contexto.

Las competencias consideradas actualmente relevantes incluyen las denominadas "competencias digitales" siendo un elemento clave a desarrollar. Las competencias digitales se las define como la capacidad de utilizar eficazmente a las herramientas de tecnológicas para dar mejora a las diferentes áreas de la vida de las personas, teniendo en cuenta el compromiso crítico y la utilización de la responsabilidad para aprender, trabajar y participar en la sociedad, con perspectivas del empoderamiento (Romero, 2017). Sin embargo, es necesario señalar que las habilidades digitales no son suficientes para lograr un desempeño profesional y educativo adecuado, pero las actitudes deben ser consideradas antes de que puedan usarse de manera efectiva.

Mediante el contexto educativo, la competencia digital se encuentra relacionada con la transferencia tanto de información, como también de creación de los espacios de innovación y éstos se han convertido en un entorno de intercambio de dialógico y de participación para el aprendizaje significativo, realizando un cambio en el escenario pedagógico actual, de tal forma que en estos intercambios y facilidad de acceso a la información generen espacios de autonomía, dejando que el proceso a la enseñanzaaprendizaje sea mucho más centrado en el alumno, haciendo que el proceso de aprendizaje tradicional se implementa en diferentes instituciones (Cáceres, Mendoza, Chua, \& Casanova, 2021). Logrando que, al mismo tiempo, que estos cambios en los enfoques educativos generan necesidades de preparar e instruir a las personas que participan en los procesos educativos, con el objetivo de formar profesionales con las habilidades necesarias que les permita desarrollarse en la actual revolución de la sociedad del conocimiento. La utilización de herramientas tecnológicas se ha convertido exactamente en una obligación para el desempeño y cumplimiento de los estándares principales de la educación superior.

Las instituciones educativas juegan un papel relevante en la promoción de la utilización y la consecución de los objetivos educativos a través estas herramientas, contribuyen al crecimiento y desarrollo científico-social. Por tanto, se establece que las competencias se han convertido en un tema de interés y al mismo tiempo de preocupación en el mundo educativo y económico, debido a que en los últimos tiempos se ha contextualizado la utilización del enfoque curricular basado en competencias, siendo una de las posibles causas de esta preocupación los resultados insatisfactorios de las evaluaciones internacionales. 
Sin embrago, según Juric, (2020) menciona que el proceso de alfabetización digital y la adquisición de determinadas competencias son las que facilitan la construcción de un individuo capaz de interactuar mediante las TIC. Uno de los informes de la OCDE (Organización para la Cooperación y Desarrollo Económico) sobre el impacto de la era digital en el bienestar de las personas menciona que la tecnología puede tener un gran impacto positivo, pero también negativo en la vida de las personas.

Así mismo, existen organizaciones como la Organización de las Naciones Unidas para la Educación, la Ciencia y la Cultura (UNESCO) que determinan a los estándares que mejor describen la competencia digital de los docentes; también, es importante recalcar que estos los estándares son usados y reconocidos a nivel internacional. Donde las competencias digitales se desagregan en seis áreas de competencia, mediante las habilidades y a través de competencias que llegan a afectar las áreas del aprendizaje, los cuales son: el compromiso profesional, recursos digitales, pedagogía digital, evaluación y retroalimentación, el empoderamiento de los alumnos y la facilitación de la competencia, por otra parte el Marco Europeo de Competencias Digitales para Educadores (DigCompEdu) (Punie, 2017) establece que los estándares que se dividen en perfiles docentes deberán desarrollarse a lo largo de la carrera profesional y de esta forma incidir en el aprendizaje y enseñanza de los estudiantes de tal forma acompañen en la práctica preprofesional. De esta forma, cada país establece un marco de referencia para el desarrollo del marco de cualificación de competencias genéricas y competencias digitales.

Según Cedano M. y Rodríguez J. (2021) la responsabilidad y desarrollo teórico, gerencial, social, ético, legal, y pedagógico, en el informe de la OCDE de 2019 se evidencia que en los países latinoamericanos como Ecuador carecen de estadísticas sobre la utilización de la tecnología, también existe una alta exposición a riesgos y una baja explotación de las oportunidades en la utilización de la tecnología. Determinando que el acceso a Internet está por encima del promedio de la OCDE y la desigualdad de utilización está por encima del promedio.

En cuanto al uso general de Internet, en 2016, el 97\% o un porcentaje mayor de la población utilizó Internet en Dinamarca, Islandia, Japón, Luxemburgo y Noruega; mientras que el $60 \%$ o un porcentaje menor lo hicieron en México y Turquía, mientras que sólo el $60 \%$ o menos lo hizo en México y Turquía. Más del $95 \%$ de los jóvenes entre 16 y 24 años interactuaron en línea contra menos del $63 \%$ de los adultos entre 55 y 74 años (OCDE, 2017).

Siendo una de las principales desventajas y riesgos del país, haciendo referencia a: las bajas competencias digitales, la baja utilización de la educación en línea, el elevado nivel de puestos de trabajo en riesgo de 
automatización y el utilizar extremadamente el internet entre las personas de 15 años.

Desde un punto de vista estudiantil, en referencia a la educación superior y las familias, se muestran situaciones de desigualdad, tanto en términos socioculturales como en términos de acceso a herramientas y materiales tecnológicos, que les facilitan el acceso, presencia y gestión adecuada de la virtualidad. Por otro lado, existe un menor nivel de alfabetización digital de docentes, estudiantes y familias, aunque la brecha de acceso a Internet se ha reducido en los últimos años, todavía existe en los grupos sociales más vulnerables y también existen brechas en las habilidades.

Según Mendoza R. (2021) en referencia a la desigualdad educativa en el contexto de la pandemia, las desigualdades latentes que se mostraron antes de la emergencia sanitaria sólo se evidencian agravadas por la educación a distancia, el autor menciona que las respuestas gubernamentales en materia de políticas públicas siguen siendo insuficientes para el apoyo tanto a los estudiantes excluidos de la educación virtual como también a los docentes.

Actualmente la educación superior a nivel mundial se ha responsabilizado por preparar a los estudiantes con una perspectiva a los logros curriculares, dejando una experiencia práctica y centrada en el empleo, por tanto, que el cumplimiento de los perfiles del egreso determinados por los programas universitarios debe ser evidente en las competencias necesarias para las necesidades de la industria y para los requisitos de las normas de acreditación. Las nuevas competencias para desarrollar han tenido un cambio rápido e imprevisto, lo cual puede afectar a los perfiles de egreso de los estudiantes como también a la necesidad de nuevas competencias para la empleabilidad, dada la incertidumbre que existe actualmente, las expectativas de habilidades serán dinámicas pero muy complejas e interdisciplinarias (Reyes, 2021).

Ante esta situación es de mucha importancia investigar y analizar el desarrollo de las competencias digitales a los estudiantes de las universidades. Por lo tanto, de acuerdo con la información recopilada, los pasos son: los procesos de mejora continua y la mejora de dichas habilidades y conocimientos.

El lugar donde se desarrolla estudio es el Instituto Superior Tecnológico Juan Bautista Aguirre Ecuatoriano, se encuentra ubicado en el Cantón Daule provincia del Guayas, el cual a raíz de la pandemia presentada llamada Covid-19 implemento el uso de plataformas virtuales para poder llevar a cabo las clases y tareas de manera eficiente y normal, brindado facilidades a los estudiantes que carecen de instrumentos tecnológicos para la realización u visualización de clases en línea. 


\section{Método}

El presente trabajo de investigación tiene como finalidad obtener una caracterización y descripción de grupos, determinando el nivel de desarrollo de las competencias digitales en una institución superior tecnológica ecuatoriana, teniendo relación con la importancia y uso de la utilización de las TICS por parte de los estudiantes, haciendo contexto de la educación superior del siglo 21. En continuidad se pretende contrastar y diferenciar estas competencias digitales en el uso diario de las TIC, también en todos aquellos servicios de Internet que los estudiantes usan para las actividades de ocio, comunicación, interacción y trabajo académico, que les ayude a desarrollar competencias. Para ello, mediante este estudio se centraran los cinco bloques del instrumento COBADI $®$ (Competencias Básicas Digitales), que se aplican a los estudiantes de una institución de educación superior ecuatoriana por medio de una encuesta por Google form (https://docs.google.com/forms/d/e/lFAIpQLSfj-wmxDujEhoivgr9il00H_CPJPK3Rvq8IPVmzwG8NO5vmg/viewform? usp $=s f \_l$ ink )(Martínez \& Pájaro, 2021).

Mediante el análisis, se utilizan inicialmente análisis estadísticos descriptivos para realizar el respectivo análisis exploratorio de los datos, el cual se usa para identificar e interpretar a los grupos según los diferentes niveles de desarrollo de habilidades digitales. Con este estudio se permitirá establecer una línea de base para un posterior análisis a profundidad de las competencias digitales que los estudiantes obtienen, con la tecnología necesaria para hacerle frente a las actividades, ya sea tanto personales o académicas, y el hábito constante del uso de las tecnologías en la docencia (proceso de aprendizaje).

La metodología que se utilizó en el presente estudio es mixta, ya que se desarrolló un análisis descriptivo y cuantitativo, donde las etapas se basan principalmente en un proceso de análisis de datos donde incluyen la siguiente:

1. Recolección de datos: Esta etapa permitirá obtener la muestra para realizar este trabajo.

2. Elaboración de datos: En esta etapa se realiza el respectivo análisis exploratorio de los datos, en el que se logra obtener estadísticas básicas, en continuidad se procede a seleccionar los atributos y las variables necesarias para el análisis de clases latentes, tanto, así como para transformar algunas de las variables a un tipo de dominio requerido.

3. Generación y evaluación de modelos: obtención de modelos preliminares de las clases latentes con diversas gráficas.

4. Análisis de resultados: Se procede a analizar los resultados que se obtuvieron, para lo cual se recurre a la observación y comparación de métricas que brindan las técnicas, luego se describe la interpretación 
de las clases y los patrones latentes obtenidos mediante la muestra de datos.

\section{Instrumento COBADI ${ }^{\circledR}$}

Los datos se recogen mediante cuestionarios, competencias Básicas Digitales e estudiantes de educación superior COBADI@, dicha marca fue registrada en la Oficina Española de Patentes y Marcas: El cuestionario COBADI ${ }^{\circledR}$ fue creado y probado por el grupo de investigación EDUINNOVAGOGiA®, el cual es reconocido por el Plan de Investigación, Desarrollo e Innovación de Andalucía y la Oficina de Transferencia de Resultados de Investigación de la Universidad Pablo de Olavide. Dicho cuestionario se divide en cinco bloques, el primero recoge datos personales de los encuestados, así como también datos sobre el consumo de tecnología (Quiñones, Martin, \& Coloma, 2021).

El bloque I corresponde a las Competencias del conocimiento y uso de las TICS en la comunicación social y el aprendizaje colaborativo, el cual se compone 12 ítems, y se evalúa mediante una escala Likert oscilando de 1 a 4 puntos, donde 1 hace referencia a "Me siento completamente ineficaz para realizar lo que se presenta" hasta 4, lo que representa "Me siento completamente efectivo". Además, se tiene la opción NS / NC / NA (NS = No sabe, $\mathrm{NC}=$ Sin respuesta, NA $=$ No aplica).

El bloque II es de las "Competencias en el uso de las TICS para la búsqueda y procesamiento de información", hace referencia a la autopercepción de la eficacia individual en el uso de herramientas TIC. El cual está compuesto por 12 ítems, que también son evaluados con una escala Likert de 1-4 puntos, donde 1 hace referencia a "Me siento completamente ineficaz para realizar lo que se presenta" hasta 4, que representa "Me siento completamente efectivo", con las opciones NS / NC / NA.

El bloque III se refiere a las "Competencias interpersonales en el uso de las TICS en el contexto universitario", determina cómo se resuelven problemas o dudas relacionados con las TIC. Está compuesto por 5 ítems, en este bloque la escala de calificación a las diferentes dimensiones anteriores, donde la opción más usada por el individuo para resolver una duda es la primera (1), luego la segunda, y de último la menos utilizada (4).

Finalmente, el bloque IV basado en las "Herramientas de comunicación virtual y social de la institución", el cual está compuesto por 5 ítems. Aquí se valora con una escala Likert de 1 a 4 puntos, donde 1 hace referencia a "Me siento completamente ineficaz para realizar lo que se presenta" hasta 4, que representa "Me siento completamente efectivo", y las demás opciones NS / NC / NA son incluido. 


\section{Población de estudio}

Para este estudio de investigación y la aplicación de la encuesta se tomó como referencia al desarrollo de la respectiva recolección de información donde se tomó como unidad de análisis a los estudiantes del Instituto Superior Tecnológico Juan Bautista Aguirre (ISTJBA), con una población de 1408 estudiantes matriculados en el II periodo académico 20202021.

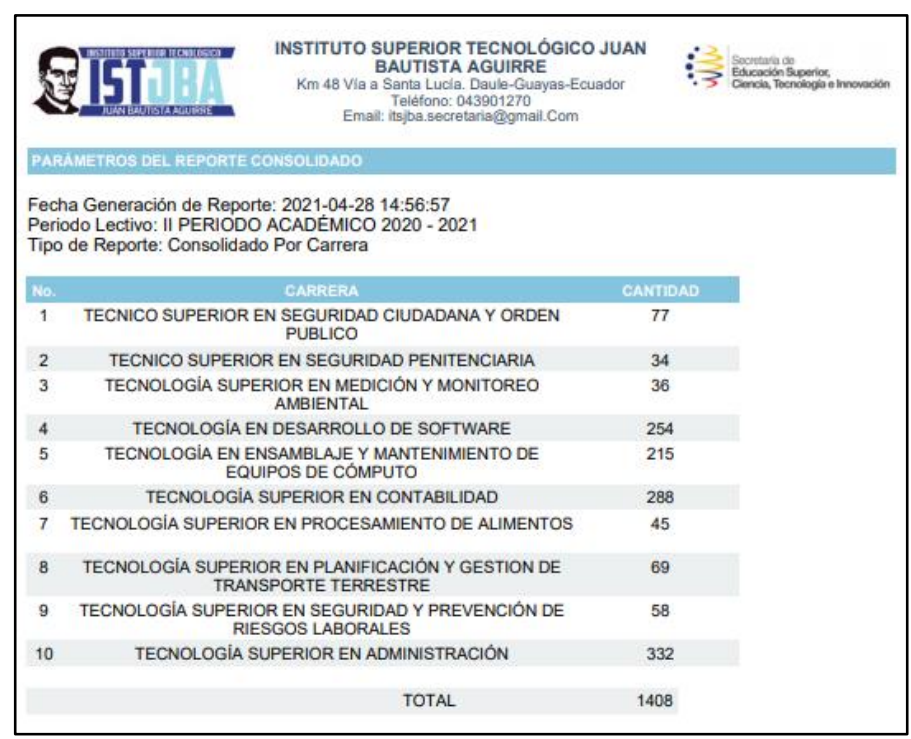

Figura 1. Población estudiantil del ISTJBA

\section{Muestra}

Se utilizó la fórmula de muestra: con un error estándar del $5 \%$ y un valor $\mathrm{Z}$ de 1,96 obteniendo una muestra de 802 .

$$
\text { Tamaño de la muestra }=\frac{\frac{z^{2} \times p(1-p)}{e^{2}}}{1+\left(\frac{z^{2} \times p(1-p)}{e^{2} N}\right)}
$$

Fórmula 1: Tamaño de la muestra

Nota: $\mathrm{N}=$ tamaño de la población $\bullet \mathrm{e}=$ margen de error (porcentaje expresado con decimales) $\bullet \mathrm{z}=$ puntuación $\mathrm{z}$ 


\section{Resultados}

\section{Pregunta 1: Edad}

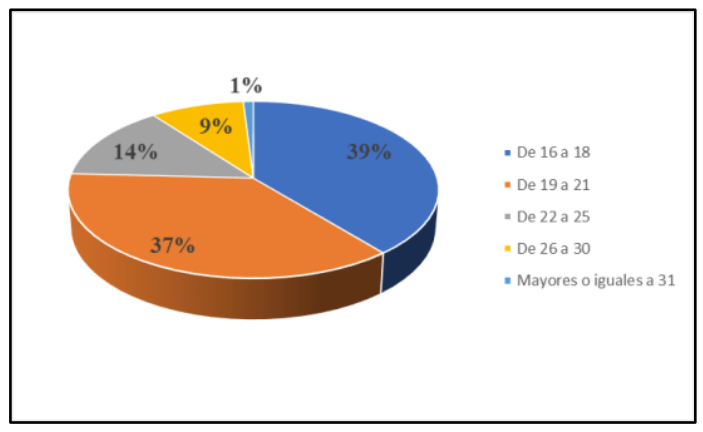

Figura 2. Edad

En cuanto a la distribución de la muestra por edades, como evidencia en la Figura 2 que la edad mínima es de 16 años y la máxima sobre pasa los 31 años, donde el primer quintil es de 18 años, la mediana es de 21 años y el tercer quintil es de 25 años, determinando que el rango de edad de 16 a 18 años denominados millenians acumula un mayor número de estudiantes siendo alrededor del $39 \%$ las observaciones, mientras en rango de edad mayor a 31 años acumula el 1\% de las observaciones.

\section{Pregunta 2: Periodo académico (semestre)}

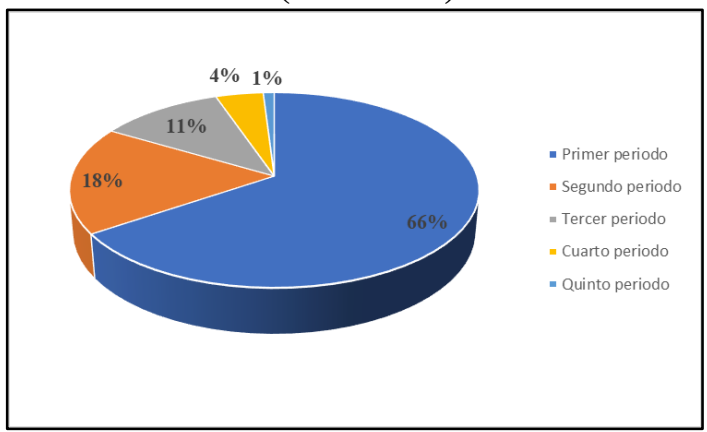

Figura 3. Periodo académico

Mediante la encuesta realizada a los estudiantes del ITSJBA se evidencia en la figura 3 resultados de la elección del periodo académico mediante el cuestionario presentado de los diferentes niveles o periodos académicos. En consecuencia, se obtuvieron resultados donde el $66 \%$ de ellos corresponden los Millenians al primer periodo o nivel, el $18 \%$ al segundo, 11 $\%$ tercero, $4 \%$ cuarto y un $1 \%$ correspondiente al quinto periodo. 


\section{Pregunta 3: Carreras}

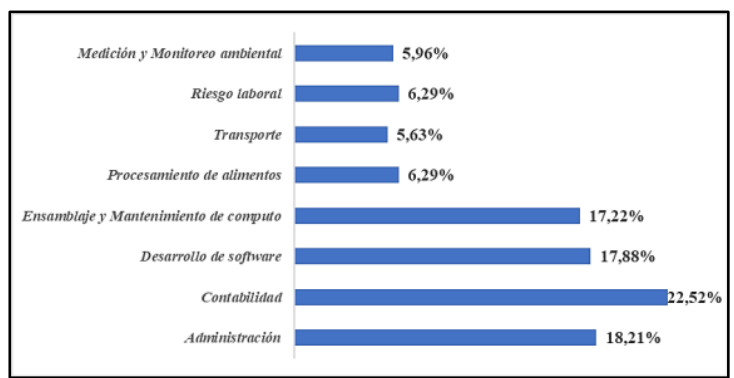

Figura 4. Carrera

La figura 4 muestra la carrera o programa de estudio que siguen los estudiantes encuestados, por tanto, se puede determinar que el 22,52\% corresponde a la carrera de contabilidad, así mismo el 18,21\% a la carrera de Tecnología Superior en Administración, el 17,88 \% a la carrera de Desarrollo de Software como también a la carrera de riesgo laboral y procesamiento de alimentos con el 6,29 \% cada una. Mientras que la carrera con menor representatividad es la de Tecnología Superior en Planificación y Gestión del Transporte Terrestre con 5,63\%.

\section{Pregunta 4: ¿Has recibido formación sobre Web 2.0 o Software social?}

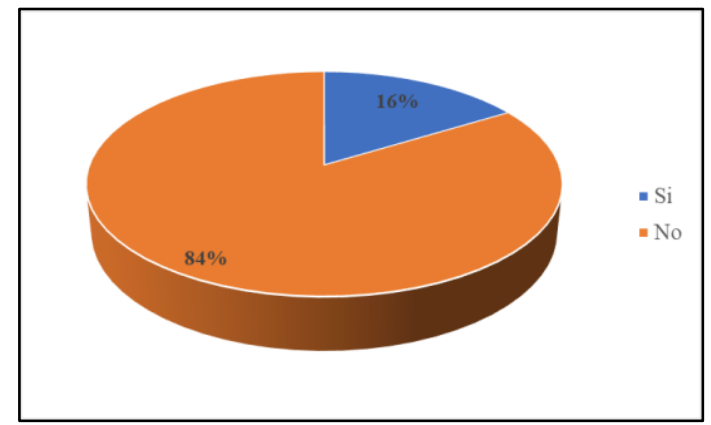

Figura 5. ¿Has recibido formación sobre Web 2.0 o Software social?

El término web 2.0 se utiliza para referirse a una nueva generación de sitios web que se permiten a las personas colaborar y compartir información online de formas que antes no eran posibles. En consecuencia, la encuesta dirigida a los estudiantes muestra que el $84 \%$ no han recibido una capacitación de este tipo. Sin embargo, tan solo el $16 \%$ describe si haber recibido una formación basada en web 2.0. 


\section{Pregunta 5: ¿Posees o no los siguientes medios tecnológicos?}

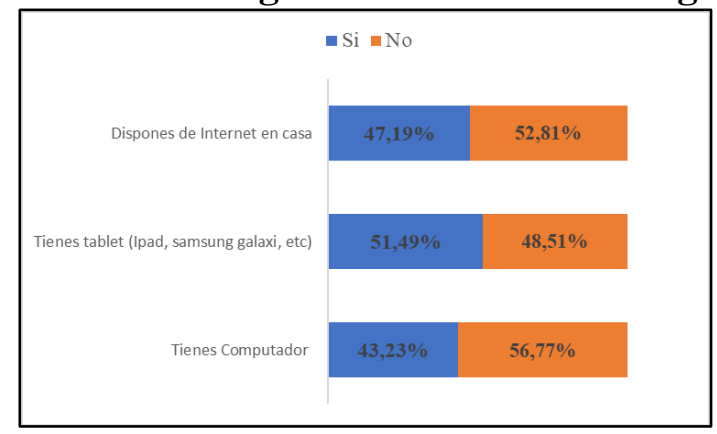

Figura 6. ¿Posees o no los siguientes medios tecnológicos?

Este ítem describe los medios a nivel tecnológicos que poseen los estudiantes, por tanto, se identifica que la disposición de internet en casa corresponde a que el 47,19\% si cuenta mientras que el 52,81 \% no. En relación con la tenencia de Tablet o algún otro dispositivo celular los encuestados determinaron que el 51,49\% si disponen de este tipo de dispositivo y el 48,51 $\%$ no. Así mismo, de quienes cuentan con un computador el $43,23 \%$ si y el $56,77 \%$ no.

\section{Pregunta 6: ¿Dónde te conectas habitualmente a Internet?}

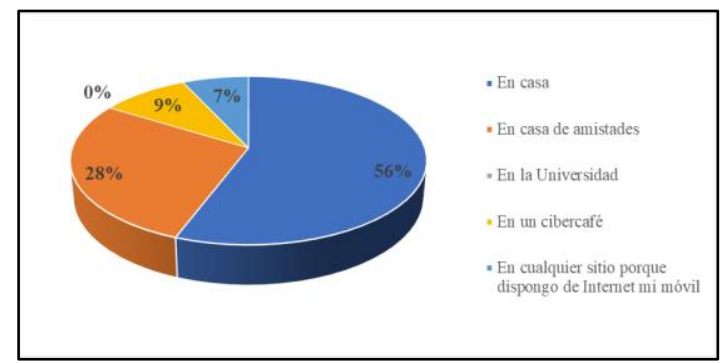

Figura 7. ¿Dónde te conectas habitualmente a Internet?

La conectividad es un insumo relevante e indispensable para la continuidad de los procesos educativos virtuales por tanto en este ítem se mide la localización habitual donde el estudiante se conecta al internet. El $56 \%$ se conecta desde casa, el $28 \%$ desde la casa de un amigo, el $9 \%$ lo hace desde un cyber café y el $7 \%$ lo puede realizar desde su dispositivo móvil ya que cuenta con servicio de internet. 


\section{Pregunta 7: ¿Cuánto tiempo dedicas a navegar por Internet?}

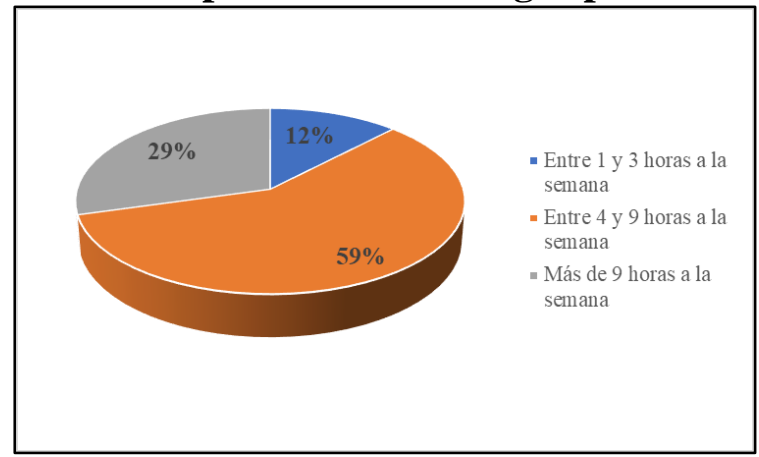

Figura 8. ¿Cuánto tiempo dedicas a navegar por Internet?

Para el desarrollo de habilidades con las TICS es imperante que el usuario genere una constante experiencia y práctica con los medios de comunicación y buscador de información como el internet. Por tanto, la encuesta midió que el mayor porcentaje (59\%) dedica tiempo al internet entre 4 a 9 horas a la semana, así mismo el $29 \%$ lo dedica más de 9 horas a la semana y tan solo el $12 \%$ entre 1 a 3 horas a la semana.

\section{Pregunta 8: ¿Cuánto tiempo utilizas Internet para las siguientes acciones?}

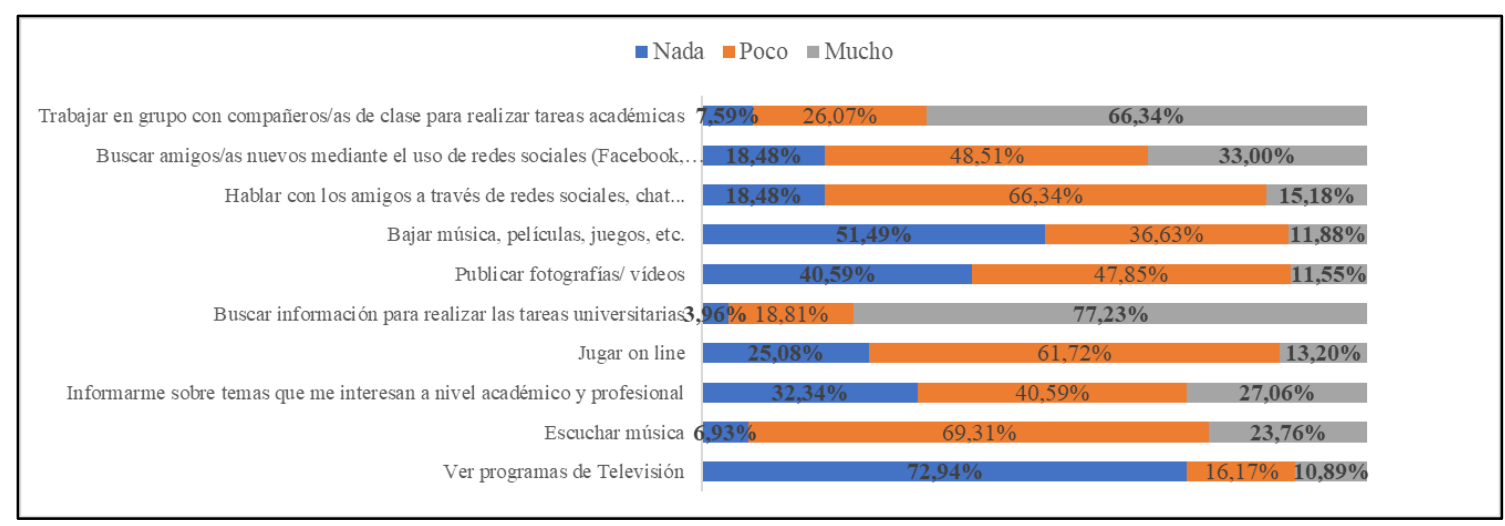

Figura 9. ¿Cuánto tiempo utilizas Internet para las siguientes acciones?

En función a las actividades realizadas durante el tiempo que se conectan los estudiantes determinan que un $66,34 \%$ se dedican a trabajar en grupo con compañeros de clase, así mismo, el 77,23 \% lo usa para buscar información y realizar así las tareas universitarias. Sin embargo, también declaran que hacen uso para socializar por medio de las redes sociales un 33 $\%$ lo hace para buscar amigos en estos medios como también el 66,34\% hace uso de redes sociales para hablar con otros amigos. Además, el 61,72 \% lo utiliza para informarse sobre temas de interés académico y profesional. 


\section{Pregunta 9: BLOQUE I: Competencias en conocimiento y uso de las TICS en la comunicación social y aprendizaje colaborativo}

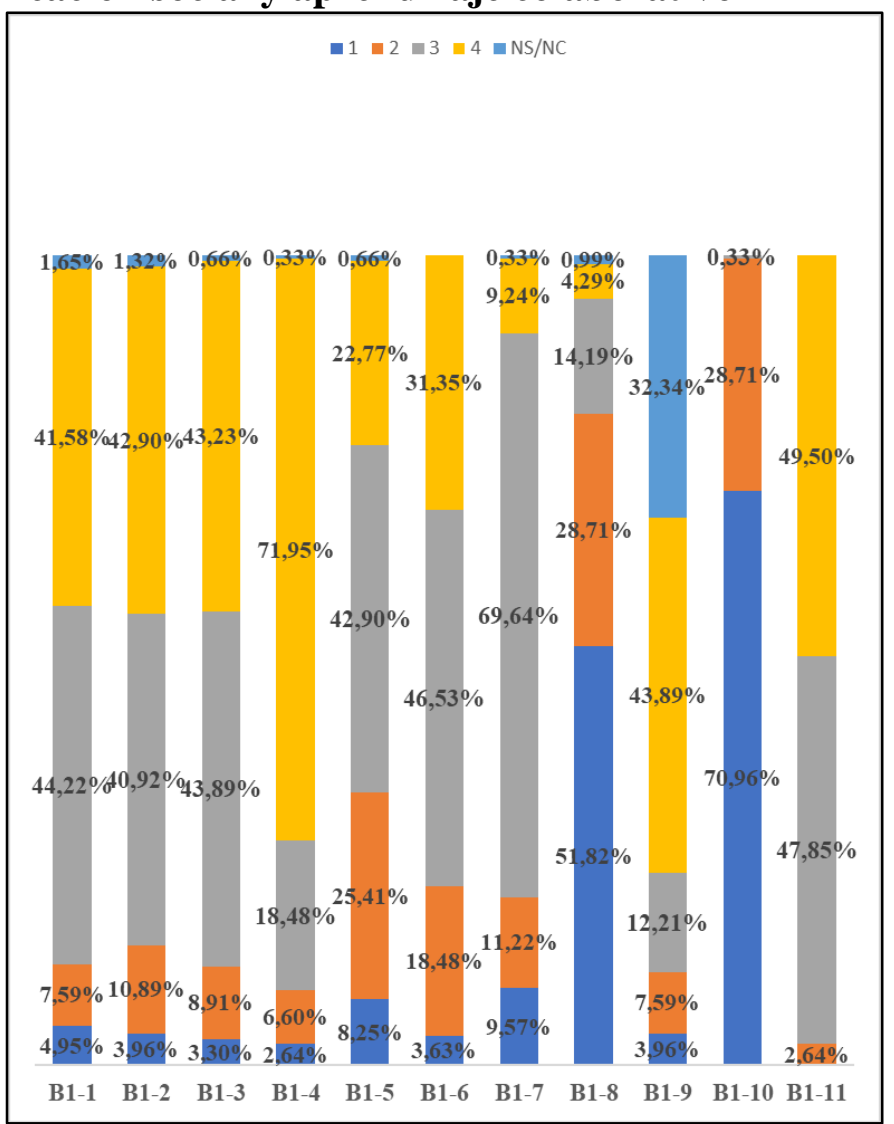

Figura 10. BLOQUE I: Competencias en conocimiento y uso de las TICS en la comunicación social y aprendizaje colaborativo

Para correlacionar las competencias en conocimiento y la utilización de las TICS en la comunicación social y aprendizaje colaborativo. Se determinó una escala que va de 1 a 4 , donde el 1 hace referencia a la percepción de completamente ineficaz para realizar lo que se presenta y el 4 sobre la percepción de lo que domina completamente. Por lo tanto, se establecieron las siguientes variables con las respectivas codificaciones:

- Se puede comunicar con otras personas mediante correo electrónico. B1-1

- Utilizo el Chat para relacionarme con más personas. B1-2

- Utilizo la mensajería instantánea como herramienta de comunicación con más personas. B1-3

- Puedo comunicarme con distintas personas participando en redes sociales (ning, facebook, twitter, hi5, myspace, tuenti, etc). B1-4 
- Soy capaz de desenvolverme en las redes de ámbito profesional (linked in, xing). B1-5

- Soy capaz de participar de modo apropiado en los foros. B1-6

- Me considero competente para participar en los blogs. B1-7

- Soy capaz de diseñar, crear y modificar Blogs o bitácoras (por ejemplo: blogger, wordpress, etc.). B1-8

- Sé utilizar las Wikis (wikipedia, aulawiki21, etc). B1-9

- Me considero competente para diseñar, crear o modificar una wiki (wikispace, nirewiki, PbWorks..., etc). B1-10

- Soy capaz de utilizar plataformas de educativas, (WebCt, campus on line, intranet, Moodle, Dokeos, etc). B1-11

Según los resultados muestran que los estudiantes consideran que las dos escalas más altas en relación con el dominio completo tienen un peso $41,58 \%$ (4) y un $44,22 \%$ (3) es decir que en total $85,90 \%$ por tanto en los estudiantes se dominan la comunicación con otras personas mediante el correo electrónico. También según la información otorgada por los estudiantes se muestra que los dos niveles que son mucho más fuertes están conformados por el 42,9 \% y 40,92 \% por tanto, quiere decir la gran mayoría si utiliza las TICS para relacionarse con otras personas. Ya que otra forma de comunicación que usan con mayor frecuencia los estudiantes está orientada a la mensajería instantánea por tanto se demuestra que el 43,23\% y 43,89\% lo dominan correctamente.

En el caso de la utilización de las redes sociales (ning, facebook, twitter, hi5, myspace, tuenti, etc) los encuestados determinan que el 71,95\% lo dominan por completo, así como también el 18,48 \% establece y describen dominar (nivel 3) las redes sociales como medio de comunicación. Por otra parte, en cuanto al dominio y el desenvolvimiento en redes sociales en el ámbito profesional (linked in, xing) los encuestados determinan que el nivel más alto de domino (4) con un $22,77 \%$, el $42,9 \%$ en el nivel 3, pero es existente un porcentaje que resulte relevante con el 18,48\% donde se ubica en el segundo nivel con el 6,6\% lo que demuestra que existe gran presencia sobre lo que los estudiantes que no dominan mediante la forma correcta dichas herramientas. En cuanto a la participación de los foros los estudiantes demuestran un buen domino por dicha razón el 31,35 \% y 42,9 \% declaran estar en ambos niveles altos de dominio.

Por tanto, también establecen que existe un buen domino para participar en blogs estimando que el 9, $24 \%$ y el 69,64\% se ubica en los niveles más altos de un dominio ( 3 y 4). Sin embargo, al consultar el dominio con respecto al diseño y creación de blogs o bitácoras los alumnos encuestados se describen con el 51,82 \%, y con el 28,71 \% desconocen o están seguros de 
cómo gestionar dichas actividades. No obstante, en referencia a la búsqueda de información en espacio virtuales como Wikipedia entre otros se determina un $32,34 \%$, y con $43,89 \%$ los encuestados determinan que si existe un dominio relacionado con la utilización de estos canales.

Sin embargo, el crear o modificar una wiki establece un 70,96 \% y $28,71 \%$ lo que determina como selección de los niveles más bajos de domino. Por otra parte, el 49,50 \% y el 47,85 \% consisten en dominar la utilización de las plataformas virtuales ya que se encuentran en los dos niveles más fuertes de un dominio de estas herramientas.

\section{Pregunta 10: BLOQUE II: Competencias de uso de las TICS para la búsqueda y tratamiento de la información}

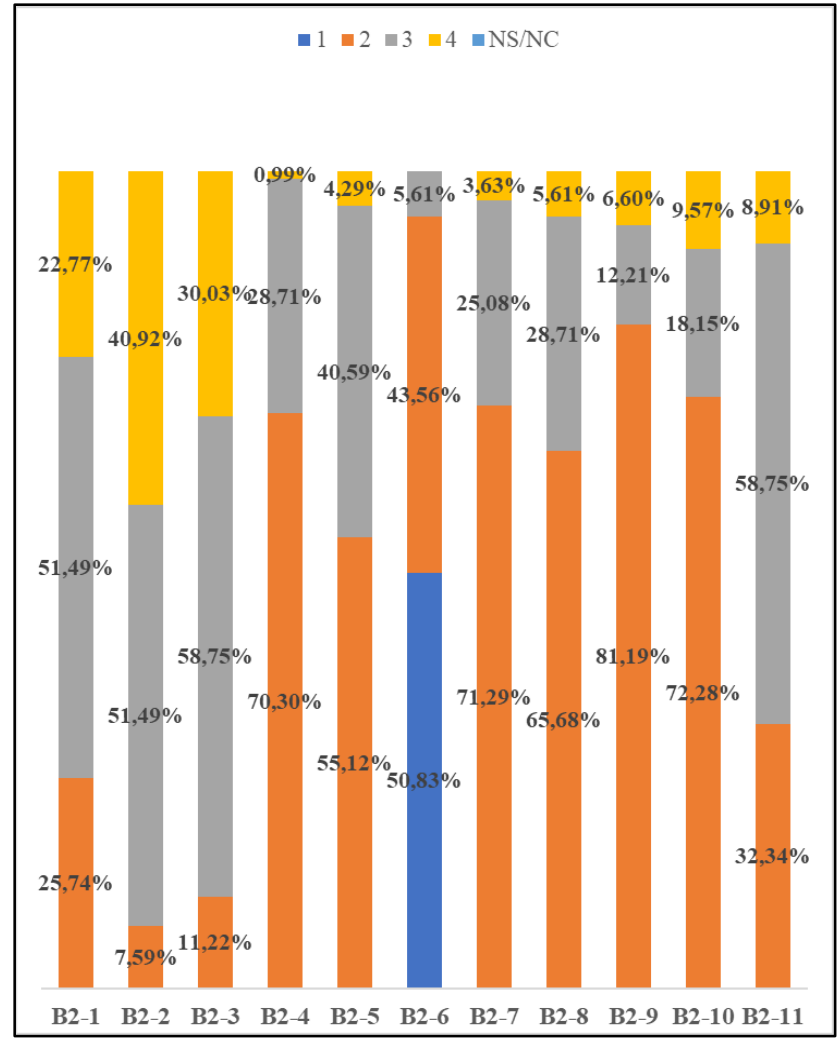

Figura 11. BLOQUE II: Competencias de uso de las TICS para la búsqueda y tratamiento de la información

En esta sección del cuestionario se establece la búsqueda de respuestas en función de la eficacia respecto al enunciado recogido en cada uno de los ítems, en continuidad, la escala va de 1 a 4 , donde el 1 se refiere a cómo te sientes completamente ineficaz para realizar lo que se presenta y el 4 consiste en creer que lo dominas completamente. También, puedes utilizar la opción 
NS/NC (por si desconoces lo que te están preguntando). Por tanto, en algunos ítems, vas a encontrar, entre paréntesis, ejemplos de aplicaciones sobre lo que preguntan para que tenga referencias, pero no están preguntando exclusivamente por las aplicaciones.

- Es posible navegar por Internet con diferentes navegadores (Mozilla, Opera, Explorer, etc.) B2-1

- Soy capaz de utilizar los distintos buscadores (google, ixquick, mashpedia, etc.) B2-2

- Me siento con capacidades para trabajar algún programa de cartografía digital para buscar lugares (google maps, google earth, vpike, tagzania, etc.) B2-3

- Sé utilizar los programas para planificar mi tiempo de estudio (google calendar...) B2-4

- Trabajo con documentos en la red (google drive, skydrive...) B2-5

- Tengo la capacidad de organizar, analizar y sintetizar la información mediante mapas conceptuales usando alguna herramienta de software social (cmaptool, mindomo, text2mindmap, bubbl...) B $\quad$ B2-6

- Puedo usar programas para difundir presentaciones interactivas en red (prezi, slideShare, scribd, etc.) B2-7

- Me siento competente para trabajar con herramientas de software social que me ayudan a analizar y/o navegar en los contenidos incluidos de los blogs (wordle, Tagxedo, ...) B2-8

- Trabajo con las imágenes mediante la utilización de las herramientas y/o aplicaciones de software social (gloster, picmonkey, animoto...) B2-9

- Me siento con capacidad de utilizar el Postcasting y videocasts (flicks, odeo, youtube, etc.) B2-10

- Utilizo códigos QR para difundir alguna información.

Las competencias consisten en disponer de habilidades para buscar, obtener, procesar y comunicar información, también para transformarla en conocimiento, donde se incluye el uso de las TICS como principal e importante elemento para estar comunicado, aprender e informarse. En síntesis, el tratamiento de la información y la competencia digital consiste en ser una persona autónoma, eficaz, responsable, crítica y reflexiva al seleccionar, logrando tratar y utilizar la información y las fuentes, así como las diversas herramientas tecnológicas, en la encuesta realizada se establece que el $81,19 \%$ de los estudiantes trabajan con las imágenes mediante la utilización de las herramientas y aplicaciones de software social, estos pueden ser: el gloster, picmonkey, animoto entre otros (B2-9), no obstante el 72,28\% 
encuestados establece que tienen la capacidad de utilizar postcasting, videocasts flicks, odeo, YouTube, entre otro (B2-10) como medio de ayuda, ya que estas herramientas digitales permiten evidenciar videos textos para resolver dudas y tareas a estudiantes.

Sin embargo, se evidencia en la tabla que el porcentaje $(58,75 \%)$ de B2-3 de los estudiantes se siente con capacidades para trabajar algún programa de cartografía digital para buscar lugares google maps, google earth, vpike, tagzania, entre otros, siendo una herramienta de beneficio, y por último, se determina el 70,30\% de los estudiante utiliza los programas para planificar su tiempo de estudio ya sea en google calendar; por tanto, se determina que las competencias de uso de las TICS para la búsqueda y tratamiento de la información son beneficios tanto para los estudiantes como para la institución debido a la gran información y ayuda que brinda.

\section{Pregunta 11: BLOQUE III: Competencias interpersonales en el uso de las TICS en el contexto universitario}

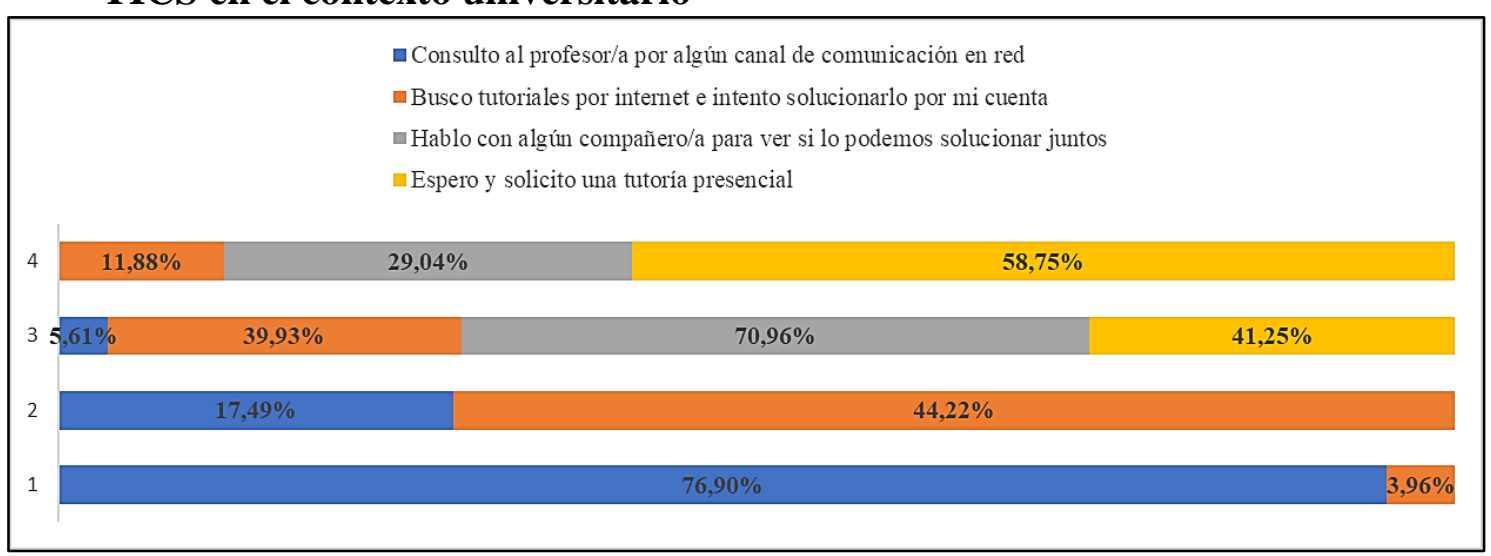

Figura 12. BLOQUE III: Competencias interpersonales en el uso de las TICS en el contexto universitario

Se debe tener en cuenta que aquí la escala tiene otro significado. Ya que primero se coloca la opción que más utilices la primera (1), luego se procede a la segunda y en último lugar la que menos uses (4) para así poder solucionar una duda. En caso de generar alguna duda sobre la utilización de algún servicio/ aplicación en red explicada en el aula se debe consultar.

- Consulto al profesor/a por algún canal de comunicación en red

- Busco tutoriales por internet e intento solucionarlo por mi cuenta

- Hablo con algún compañero/a para ver si lo pueden solucionar juntos

- Espero y solicito una tutoría presencial

Con el pasar de los años grandes cambios han acontecido durante la vida cotidiana debido a la introducción de las tecnologías de la información y 
la comunicación (TIC), llevándonos a aventurar en la Sociedad de la Información, en la encuesta realiza a los estudiantes del Instituto Superior Tecnológico Juan Bautista Aguirre se determinó que el 76, 90\% consulto al profesor por algún canal de comunicación en red (1), la incorporación de las TICS en los procesos de enseñanza-aprendizaje, se han encargado de cumplir el papel de mediadores y facilitadores de la comunicación, ya que se ha producido de manera masiva, por el carácter 'innovador', motivador, favorecedor de enseñar, por si la llegada masiva y persistente de la red tecnológica al ámbito de la didáctica nos abre, al menos, a la reflexión de usabilidad, es decir, por este medio los docentes despejan dudas, ayudan y brindan información, comunicación entre alumnos y maestros.

La mayor parte de los estudiantes tienen la facilidad de resolver tareas, problemas, dudas e investigaciones por medio del internet, debido al avance tecnológico que existe, por esa razón los encuestados determinaron que el $44,22 \%$ busca tutoriales por internet e intenta solucionarlos por su propia cuenta (2) debido a que existe demasiada información en el internet lo cual permite que los estudiantes obtengan respuestas a lo buscado, no obstante el $70,96 \%$ hablo con algún compañero para ver si lo pueden solucionar juntos (3), esta situación se presenta a raíz que así como existen alumnos que tienen conocimientos sobre el uso de las TICS en educación, también existen alumnos que no tienen el pleno conocimiento de la ayuda y beneficios de la tecnología de comunicación e información, por tanto, algunos de ellos prefieren realizar las tareas con ayuda de otros compañeros o entre si ayudarse. Sin embargo, en esta encuesta se determinó que 58,75\% el Espera y solicita una tutoría presencial (4), haciendo referencia a que ese porcentaje de estudiantes se alinea a despejar las duda o resolver los problemas presentados en las clases por medio de tutorías con los docentes, es decir que evita relacionarse con el usa de las TICS en educación ya sea por desconocimiento o por falta de interés. 


\section{Pregunta 12: BLOQUE IV: Herramientas virtuales y de comunicación social de la institución}

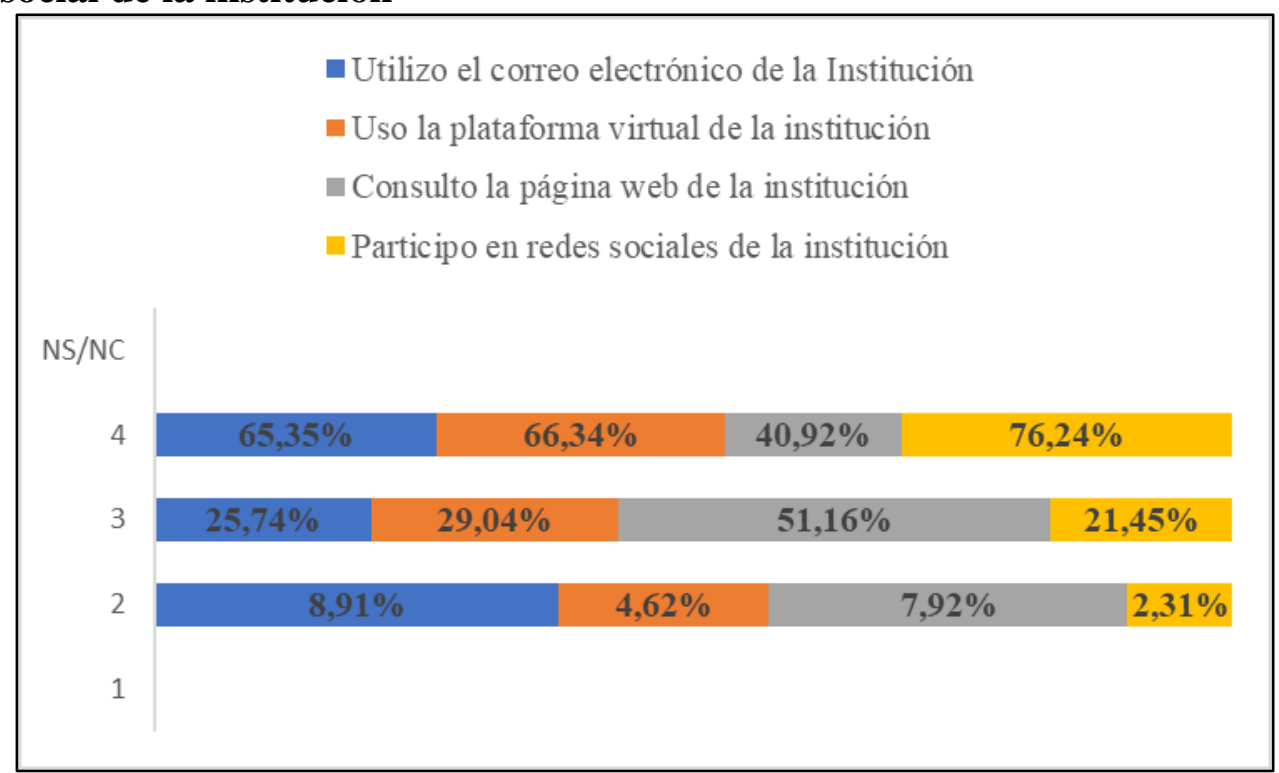

Figura 13. BLOQUE IV: Herramientas virtuales y de comunicación social de la institución

Este bloque está centrado en el conocimiento y la utilización que tengas sobre las herramientas virtuales y de comunicación social del ITSJBA. Se debe tener claro lo que significa la escala: La escala va de 1 a 4 , ya que en 1 es el que hace referencia a que se sienten completamente ineficaz para realizar lo que se presenta, no obstante, el 4 considera que dominas completamente. Sin embargo, se puede utilizar la opción NS/NC (por si desconoces lo que están preguntando). Respecto a las herramientas que se enuncian a continuación, índica el nivel de eficacia que posees en su uso.

- Utilizó el correo electrónico de la Institución

- Uso la plataforma virtual de la institución

- Consulto la página web de la institución

- Participo en redes sociales de la institución

Según la encuesta realizada a los estudiantes del Instituto Tecnológico Superior Juan Bautista Aguirre se determina 65,35 \% Utilizó el correo electrónico de la institución (1), es decir, este porcentaje de alumnos, utiliza el correo de la institución para enviar datos o información necesaria, también por medio del correo envían las quejas dudas referente a la institución, el $74,24 \%$ participo en redes sociales de la institución, el cual determina que los estudiantes si forman parte de las redes sociales del instituto.

Por tanto, el uso de la plataforma virtual de la institución es del 66,34 $\%$ según los encuestados establecen es de utilidad la plataforma virtual debido 
a que por ese medio suben tareas, evidencian videos, grabaciones hasta incluso test, en la actualidad es de muy importante contar con un sistema o plataforma que sirva de ayuda a los estudiantes y docentes de la institución, mientras el $40,92 \%$ de los estudiantes determina que si consultan la página web de la institución para algún tipo de información necesaria, ya que debido a la pandemia han existido demasiados cambios en referencia a educación.

\section{Conclusiones}

Las nuevas perspectivas y transformaciones educativas que se dan mediante los nuevos avances tecnológicos necesitan un mayor énfasis que les permita mejorar los procesos de enseñanza, teniendo en cuenta que la competencia digital es una de las competencias importante de este siglo 21, donde las instituciones de educación superior deberán repensar las formas de desarrollar los nuevos roles profesionales los cuales son requeridos en la sociedad y las nuevas maneras relacionales de los individuos para de esta forma satisfacer los requerimientos ocupacionales emergentes ante la sociedad del conocimiento. Estos nuevos requerimientos laborales y sobre todo las demandas comunicativas de las nuevas tecnologías determinan en nuestra vida diaria, lo que también beneficia y facilita el desarrollo de futuros profesionales.

Sin embargo, hay que recorrer mucho para cerrar las brechas entre las habilidades digitales existentes y las habilidades que son necesarias bajo las demandas de los nuevos espacios de trabajo. En continuidad, el presente trabajo se centró en una muestra de estudiantes del Instituto Tecnológico Superior Juan Bautista Aguirre, en el cual el estudio nos permite establecer una línea de base para así poder continuar con un similar análisis de competencias digitales con los estudiantes del instituto ecuatoriano en el futuro, con el fin de establecer un lazo existente en ambos grupos. Es de mucha importancia que se enfatice la necesidad de incrementar las competencias digitales para impactar los indicadores de una educación compleja, lo cual avanza con destino hacia los escenarios competitivos y donde es posible sostenerse a sí mismo, esto es sólo si la utilidad de la tecnología es comprendida bajo un enfoque creativo y crítico.

Para los estudiantes de educación superior tecnológico en Ecuador, es recomendable que, como intervención educativa, pueden ingresar a cursos de TICS los cuales le ayudaran y les permitirá mejorar las habilidades digitales. El instrumento que facilitó enormemente el análisis del cuestionario es el COBADI ${ }^{\circledR}$, ya que este tipo de análisis permitió generar un número aceptable de modelos y ajustarlos hasta que sea visible un modelo apropiado. Las métricas BIC y AIC mostraron ser buenos criterios para ajustar los modelos y encontrar el número óptimo de clases latentes, las cuales pueden describir el conjunto de datos. Sin embargo, uno de los problemas principales del uso de 
estos criterios es que a veces pueden mostrar que hay demasiadas clases latentes, por tanto, esto dificulta la interpretación de los datos.

\section{References:}

1. Aguiar, B., Velázquez, R., \& Aguiar, J. (2019). Innovación docente y empleo de las TIC en la Educación Superior. Espacios.

2. Amaro, R. (2020). La planificación didáctica y el diseño instruccional en ambientes virtuales. Universidad Pedagógica Experimental Libertador, Caracas-Venezuela.

3. Avila, K. (2019). Aplicaciones móviles educativas en el desarrollo de la comprensión auditiva del idioma inglés. Universidad Central del Ecuador.

4. Bedregal, N., \& Cornejo, V. (2019). Evaluación de la percepción estudiantil en relación al uso de la plataforma Moodle desde la perspectiva del TAM. Ingeniare. Revista chilena de ingeniería, 707718.

5. Burden, K., \& Kearney, M. (2017). Investigating and critiquing teacher educators' mobile learning practices. Interactive Technology and Smart Education. doi:10.1108/ITSE-05-2017-0027

6. Cáceres, S., Mendoza, M., Chua, A., \& Casanova, E. (2021). Consideraciones para desarrollar competencias digitales de investigación en un ambiente virtual.

7. Carneiro, R., Toscano, J., \& Díaz, T. (2021). Los desafíos de las TIC para el cambio educativo. Fundación Santillana.

8. Castillo, A., Peña, H., Avalos, P., Méndez, M., \& Macías, A. (2017). Las competencias TIC en Educación. Descripción de las competencias digitales en los alumnos de nuevo ingreso. Revista Electrónica sobre Tecnología, Educación y Sociedad.

9. Castro, S., \& Guzmán, B. (2007). Las Tic en los procesos de enseñanza y aprendizaje. Revista de Educación Laurus, 213-234.

10. Cavaller, V. (2016). La tecnología cognitiva. Recuperado de https://n9.cl/6yegk.

11. Cedano, M., \& Rodríguez, J. (2021). Plataforma virtual como herramienta didáctica en el currículo de la asignatura inglés del nivel secundario. UCE Ciencia. Revista de postgrado.

12. Chee, T., Chan, C., Bielaczyc, K., Ma, L., Scardamalia, M., \& Bereiter, C. (2021). Construcción de conocimiento: alineando la educación con las necesidades de creación de conocimiento en la era digital. Investigación y desarrollo de tecnología educativa. doi:https://link.springer.com/article/10.1007/s11423-020-09914-x 
13. Chiquinquirá, R., \& Hernández, J. (2020). M-Learning: Estrategia Para La Promoción Del Aprendizaje Electrónico Móvil En Instituciones De Educación Superior. Universidad Privada Dr. Rafael Belloso Chacín.

14. Coll, C., \& Monereo, C. (2008). Psicología de la educación virtual. Ediciones Morata.

15. Cruz, A., Aguilar, A., Colomo, E., Gabarda, E., \& Domínguez, R. (2018). Propuesta Multidiciplinares de innovacón e intervención educativa. Universidad Internacional de Valencia.

16. Diez, C., \& Cabrera, L. (2021). La educación virtual en tiempos de la pandemia COVID-19: Un reto docente. CIENCIAMATRIA.

17. Escobar, J., \& Mira, Y. (2020). Las competencias digitales básicas en estudiantes del Cibercolegio UCN: construcción de cultura digital. Revista Reflexiones y Saberes.

18. Gallegos, J. (2015). Las Prácticvas Pedagógicas que realizan los asistentes de la educación, durante los recreos en los patios de la escuela públicas Básicas de Valparaíso y su relevancia en la gestión de la convivencia. Universidad Autónoma de Barcelona, 22-48.

19. García , R., \& Corona, J. (2020). M-learning: strategy for the promotion of mobile e-learning in higher education institutions. Universidad Privada Dr. Rafael Belloso Chacín.

20. Gewer, A., \& Montero, L. (2015). Colaboración y redes sociales en la enseñanza universitaria. Revista Científica de Comunicación y Educación.

21. González, D. (2017). Ambientes colaborativos virtuales para el aprendizaje individual. Universidad de Costa Rica, 1-29.

22. González, R., \& Medina, G. (2018). Uso de dispositivo móviles como herramientas para aprender. Pixel-Bit: Revista de Medios y Educación, 217-227.

23. Hernández, R., \& Morales , M. (2010). Dispositivos móviles en educación. Revista América Learning \& Media. Recuperado de https://n9.cl/ael6e.

24. Herrera, B. (2012). El móvil en la educación: Un nuevo paradigma. Ventajas y desventajas de su uso. Recuperado de https://n9.cl/hxw5m.

25. Herrera, M. (2018). El refuerzo pedagógico como herramienta para el mejoramiento de los. Universidad Andina Simón Bolívar, 17-30.

26. Huizar, M., \& De la Torre, Y. (2020). Aprendizaje autorregulado: las tecnologías de información y comunicación (tic) y la lectura en la educación superior. Red de Investigación Educativa, 12(2), 31-45.

27. Jubany i Vila, J. (2012). Sistema de Información Científica. Pixel-Bit. Revista de Medios y Educación, 239-240.

28. Juric, V. (2020). TIC, educación y nueva normalidad: Miradas (RE) creativas para un futura (IN) cierto. Virtualidad, Educación y Ciencia. 
29. Landon, b. (1989). online Educational delivery Applications: a web tool for comparative analysis. Obtenido de $\mathrm{http}: / / \mathrm{www} . \mathrm{c} 2 \mathrm{t} 2 . \mathrm{ca} /$ landonline/

30. Leiva, A. (2016). La metodología M-learning en el desarrollo de la escucha del idoma inglés. Universidad Central del Ecuador.

31. Luna, J. (2021). Tecnologías de Información, Comunicación y Conocimiento para el Aprendizaje Digital (TICCAD) en tiempos de pandemia: un balance crítico desde los imaginarios de la sosteniblidad. Universidad Pablo de Olavide-CICSAHL-Kresearch, 35-63.

32. Marqués, P. (2013). Claves para mejorar los aprendizajes integrando las tecnologías móviles en las clases" en Tecnología móvil e innovación en el aula. Nuevos retos y realidades educativas. Universidad de La Rioja. Recuperado de https://n9.cl/aulz.

33. Martínez, G., \& Garcés, F. (2020). Competencias digitales docentes y el reto de la educación virtual derivado de la covid-19. Educación y Humanismo.

34. Martínez, R., \& Pájaro, M. (2021). formación docente, practicas pedagogicas y competencias digitales del maestro y estudiantes en la era de la información.

35. Mauri, T., onrubia, J., Coll, C., \& Colomina, R. (2016). La calidad de los contenidos educativos reutilizables: diseño, usabilidad y prácticas de uso. Revista de Educación a distancia, 50, 1-9.

36. Mejía, M. (2020). M-Learning: Uso, características, ventajas y desventajas. Revista internacional tecnológica-educativa docentes 2.0.

37. Mendoza, R. (2021). Competencias digitales en estudiantes de secundaria bajo un sistema educativo virtualizado.

38. Ministerio de Educación. (2017). Enfoque de la Agenda Educativa Digital. Quito. Obtenido de www.educacion.gob.ec

39. Mujica, R. (2020). E-Learning como estrategia pedagógica en la educación superior. Revista Tecnológica Educativa Docentes.

40. Naranjo, E. C. (2019). Estrategia de formación virtual basada en el modelo ADDIE para fortalecer competencias pedagógicas y tecnológicas de los docentes del colegio WESLEYANO NORTE. Universidad EAN, 30-42.

41. OCDE. (2017). https://www.oecd.org/centrodemexico/medios/elacceso-y-utilizacion-desiguales-podrian-frenar-el-potencial-de-laeconomia-digital-ocde.htm.

42. Oeganización Mundial del Comercio. (2018). El futuro del comercio mundial: cómo las tecnologías digitales están transformando el comercio mundial. Organizacón Mundial del Comercio. 
43. Ortiz, A., Colón, J., \& AgredaI, M. (2018). Gamificación en educación: una panorámica sobre el estado de la cuestión. Scielo, 2-5.

44. Pérez-berenguer, d., \& garcía-Molina, J. (2016). Un enfoque para la creación de contenido online interactivo en las instituciones universitarias. Revista Educación a distancia, 51, 1-24.

45. Pinares, M. (2018). Autoeficacia computacional y uso académico de TIC en estudiantes universitarios. PUCP.

46. Pujals, P. (2018). Modelo de comunicaciòn para la enseñanza a distancia en internet. Universidad Autonoma de Barcelona, 14-31.

47. Punie, Y. (2017). European Framework for the Digital Competence of Educators: DigCompEdu. EUR 28775 EN, Publications Office of the European Union, Luxembourg: Redecker, C. doi:doi:10.2760/178382 (print), 10.2760/159770

48. Quiñones, N., Martin, C., \& Coloma, M. (2021). Rendimiento académico y factores educativos de estudiantes del programa de educación en entorno virtual. .

49. Reyes, C. (2021). Competencias digitales básicas para garantizar la continuidad académica provocada por el Covid- 19.

50. Rincón, A. (2016). Practicas inovadoras de investigación educativa de TIC que posibilitan el desarrollo profesional docente. Universidad Autónoma de Barcelona, 31-36.

51. Rodríguez, E. (2018). Importancia del manejo de competencias tecnológicas en las prácticas docentes de la Universidad Nacional Experimental de la Seguridad (UNES). Universidad De Costa Rica, 25.

52. Romero, P. (2017). Las competencias digitales y las problemáticas actuales frente a las clases virtuales en los estudiantes universitarios en tiempos de COVID19.

53. Rozas, A., \& Rojas, T. (2016). Diseño y validación de una herramienta tecnológica dirigida a pymes para realizar autodiagnósticos sobre el cumplimiento de requisitos de la Norma Pyme y la Norma Nacional para demostrar la carbono-neutralidad en Costa Rica. Tecnología en Marcha, 110-124.

54. Salas, C. (2020). Estrategia didáctica para fortalecer habilidades digitales en los estudiantes de educación virtual del IDPAC.

55. Sánchez, M., \& Pinochet, G. (2017). El rol de las redes sociales virtuales en la difusión de información y conocimiento: estudio de casos. https://www.redalyc.org/revista.oa?id=1872, 107-135.

56. Segura, R., \& Escudero, N. (2017). Ejes de desempeño y competencias digitales para docentes en una institución mexicana de educación superior. In IV Jornadas de TIC e Innovación en el Aula. 
57. UNESCO. (2019). Recomendación sobre los Recursos Educativos Abiertos (REA). Organización de las Naciones Unidas para la Educación, la Ciencia, y la Cultura, 1-5.

58. Valencia, n., huertas, A., \& baracaldo, P. (2014). Virtual learning environments: review of publications between 2003-2013 from the evidence-based pedagogy perspective. Revista Colombiana de Educación, 66, 73-103. 